\title{
Salmonella Typhimurium Invalidated for the Three Currently Known Invasion Factors Keeps Its Ability to Invade Several Cell Models
}

\author{
Sylvie M. Roche ${ }^{1 * \neq}$, Sébastien Holbert ${ }^{1 \neq}$, Jérôme Trotereau ${ }^{1}$, Samantha Schaeffer ${ }^{1,2+}$, \\ Sonia Georgeault ${ }^{3}$, Isabelle Virlogeux-Payant ${ }^{1}$ and Philippe Velge ${ }^{1}$ \\ ${ }^{1}$ ISP, Institut National de la Recherche Agronomique (INRA), UMR 1282, Université de Tours, Paris, France, ${ }^{2}$ INSERM UMR \\ 1162, Institut de Génétique Moléculaire, Paris, France, ${ }^{3}$ Plateforme des Microscopies, Université et CHRU de Tours, Tours, \\ France
}

To establish an infection, Salmonella has to interact with eukaryotic cells. Invasion of non-phagocytic cells (i.e., epithelial, fibroblast and endothelial cells) involves either a trigger or a zipper mechanism mediated by the T3SS-1 or the invasin Rck, respectively.

OPEN ACCESS

Edited by:

Stephanie M. Seveau,

The Ohio State University,

United States

Reviewed by:

Brian Ahmer,

The Ohio State University,

United States

Victor H. Bustamante,

Universidad Nacional Autónoma de

México, Mexico

${ }^{*}$ Correspondence:

Sylvie M. Roche

sylvie.roche@inra.fr

${ }^{\dagger}$ Present Address: Samantha Schaeffer, INSERM UMR 1162, Institut de Génétique

Moléculaire, Paris, France

¥These authors have contributed equally to this work

Received: 18 May 2018

Accepted: 23 July 2018

Published: 10 August 2018

Citation:

Roche SM, Holbert S, Trotereau J,

Schaeffer S, Georgeault S,

Virlogeux-Payant I and Velge P (2018)

Salmonella Typhimurium Invalidated

for the Three Currently Known

Invasion Factors Keeps Its Ability to Invade Several Cell Models.

Front. Cell. Infect. Microbiol. 8:273.

doi: 10.3389/fcimb.2018.00273 Another outer membrane protein, PagN, was also implicated in the invasion. However, other unknown invasion factors have been previously suggested. Our goal was to evaluate the invasion capability of a Salmonella Typhimurium strain invalidated for the three known invasion factors. Non-phagocytic cell lines of several animal origins were tested in a gentamicin protection assay. In most cells, we observed a drastic decrease in the invasion rate between the wild-type and the triple mutant. However, in five cell lines, the triple mutant invaded cells at a similarly high level to the wild-type, suggesting the existence of unidentified invasion factors. For the wild-type and the triple mutant, scanning-electron microscopy, confocal imaging and use of biochemical inhibitors confirmed their cellular uptake and showed a zipper-like mechanism of internalization involving both clathrin- and non-clathrin-dependent pathways. Despite a functional T3SS-1, the wild-type bacteria seemed to use the same entry route as the mutant in our cell model. All together, these results demonstrate the existence of unknown Salmonella invasion factors, which require further characterization.

Keywords: T3SS-1, T3SS-1 independent invasion, zipper, trigger, entry mechanism, cell models

\section{INTRODUCTION}

Salmonella enterica serovar Typhimurium (S. Typhimurium) is one of the broad host range serotypes incriminated in food-borne diseases in industrial countries. In the European Union, over 90,000 salmonellosis cases are reported every year (EFSA., 2017) and between 2008 and 2013 in France, Salmonella spp ranked as the third cause of foodborne illnesses (12\%), as the second cause of hospitalization (24\%), and as the first cause of death (27\%) (Van Cauteren et al., 2017). The bacteria are commonly found in the intestinal tracts of healthy birds and mammals, resulting in a spectrum of outcomes ranging from severe systemic disease to asymptomatic carriage (Velge et al., 2012). In calves, the Typhimurium serovar causes enterocolitis, and infected animals can succumb to dehydration. In newly hatched chicks, it causes systemic disease and diarrhea, whereas older chickens are asymptomatic carriers. It could also be responsible for a typhoid fever like disease in susceptible mouse strains (Santos et al., 2001). 
Salmonella is a facultative intracellular bacterium/pathogen able to interact with and to invade non-phagocytic eukaryotic cells both in vitro and in vivo (Finlay and Brumell, 2000; De Jong et al., 2012). Invasion of these cells is considered as one of the most important steps of Salmonella pathogenesis. The most extensively investigated invasion mechanism requires the Type III Secretion System-1 (T3SS-1) encoded by the Salmonella pathogenicity island 1 (SPI-1), a needle-like structure which directly injects bacterial effector proteins into the host cell cytoplasm to manipulate cell signaling pathways leading to actin cytoskeletal rearrangement and bacterial internalization (Ly and Casanova, 2007). The T3SS-1 mediates invasion by a trigger mechanism, corresponding to intense membrane ruffling which envelops the bacterium, and leads to its internalization (Francis et al., 1992). Other entry mechanisms involving Rck and PagN, two outer membrane proteins, have been described in Salmonella (Heffernan et al., 1994; Heithoff et al., 1999; Lambert and Smith, 2008).

Rck is poorly expressed in vitro under standard culture conditions, but its expression is induced by quorum-sensing and controlled through the quorum-sensing transcriptional regulator SdiA (Abed et al., 2014). The epidermal growth factor receptor has been identified as the cell signaling receptor required for Rck-mediated adhesion and internalization (Wiedemann et al., 2016). Rck invasion induces a local accumulation of actin, leading to discrete membrane rearrangements, characteristic of a zipper entry process (Rosselin et al., 2010). The second outer membrane protein, PagN is another invasin, whose expression is regulated by the two-component regulatory system PhoP-PhoQ. Acidic $\mathrm{pH}$ and a low $\mathrm{Mg}^{2+}$ concentration are required for its optimal in vitro expression (Lambert and Smith, 2008). PagN of S. Typhimurium utilizes heparinated proteoglycans to invade mammalian cells (Lambert and Smith, 2009). Salmonella is therefore the first bacterium known to be able to induce both zipper (Rosselin et al., 2010) and trigger mechanisms to invade host cells.

For a long time, T3SS-1 was considered as the only invasion factor. However, several studies have shown that a SPI-1 or a invA mutant remains invasive and pathogenic in vivo (Murray and Lee, 2000; Hapfelmeier et al., 2005; Desin et al., 2009) and in vitro (Aiastui et al., 2010; Radtke et al., 2010; Van Sorge et al., 2011). Moreover, a T3SS-1 mutant cultivated in conditions which do not allow the expression of Rck and PagN keeps its ability to invade some cells (Rosselin et al., 2011). Although clear evidence is lacking, all these papers tend to suggest the existence of unknown entry routes.

The cellular internalization of exogenous particles is a physiological process and distinct internalization pathways have been identified in mammalian cells. Endocytosis is a well-documented phenomenon (Le Roy and Wrana, 2005; Sigismund et al., 2012). An example is macropinocytosis, a receptor-independent endocytic pathway, which is associated with actin-dependent plasma membrane ruffling (Maréchal et al., 2001; Hänisch et al., 2012). In clathrin-mediated endocytosis, transmembrane receptors bind with their ligands and are clustered into clathrin-coated pits (Mcmahon and Boucrot, 2011) resulting in the formation of vesicles, which are either recycled to the surface membrane or fuse with lysosomes. Another pathway is clathrin-independent but lipid-raft dependent that includes caveolae, which are small vesicles enriched with caveolin, cholesterol and sphingolipids (Parton and Richards, 2003; Le Roy and Wrana, 2005). These endocytic entry processes are used by numerous bacteria and viruses to invade cells (Cossart and Helenius, 2014). As multiple endocytic pathways exist in a single cell, the development of specific inhibitors has helped in identifying the molecules involved in the cross-talk between these pathways (Mayor et al., 2014).

The aim of our study was to identify the invasion capabilities of the S. Typhimurium 14028 strain and its isogenic triple mutant invalidated for its T3SS-1 $(\triangle i n v A)$ and deleted for the genes encoding the invasion factors Rck and PagN ( $\triangle i n v A:: k a n$ $\Delta p a g N:: c m \Delta r c k)(S T M-3 \Delta)$. Different non-phagocytic cell lines and primary cells from several animal origins, representing cell types encountered by Salmonella within their hosts were used to evaluate the relative importance of the known invasion factors.

\section{MATERIALS AND METHODS}

\section{Bacterial Strains and Plasmids}

The different bacteria and plasmids used are described in Table $\mathbf{1 .}$ The bacterial strains were maintained in TSB (Tryptic Soy Broth-Difco)-glycerol (25\%) at $-80^{\circ} \mathrm{C}$. For the invasion assays, bacteria were first subcultured in TSB at $37^{\circ} \mathrm{C}$ for $7-8 \mathrm{~h}$ with shaking in the presence of carbenicillin $(100 \mu \mathrm{g} / \mathrm{mL})$, kanamycin $(50 \mu \mathrm{g} / \mathrm{mL})$, chloramphenicol $(30 \mu \mathrm{g} / \mathrm{mL})$ and nalidixic acid $(100 \mu \mathrm{g} / \mathrm{mL})$ when required. The bacteria were then grown overnight in TSB without shaking and bacteria concentrations were standardized turbidimetrically and diluted appropriately in cell culture medium.

\section{Construction of the Different Mutants}

Deletion of the invA, rck and $p a g N$ open reading frames was performed using the $\lambda$ Red recombinase method (Datsenko and Wanner, 2000) using primers described in Table 1. Three colonies of each mutant (STM-3 $\Delta$ and STM- $\Delta$ invA) were cultivated, stocked in $25 \%$ of glycerol at $-80^{\circ} \mathrm{C}$, and checked by PCR and sequencing (Beckman Coulter).

\section{Eukaryotic Cells and Culture Conditions}

Epithelial cells from different species were tested: human colon adenocarcinoma HT-29 (ECACC), human hepatocyte carcinoma Hep G2 (ECACC), human cervical carcinoma cell line HeLa (ATCC CRM-CCL-2), minipig male ileum IPI-2I (ECACC), chicken hepatocellular carcinoma LMH (ATCC), African green monkey kidney Ma-104 (ATCC), human colon adenocarcinoma Caco-2 (ATCC), new-born piglet intestinal IPEC-1 (GonzalezVallina et al., 1996) and murine hepatocyte AML-12 (ATCC). Three endothelial cell lines were also used: human brain microvascular endothelial cells HBMEC [kindly donated by Dr. C. Kieda (Centre de Biophysique Moléculaire, CNRS, Orléans, France)], human proliferating umbilical vein endothelial cells, HUVEC-p (PromoCell) and chicken aortic endothelial cells chAEC (Lion et al., 2017). Fibroblasts from different animal origins were also included: mouse primary kidney cloned, termed finite cell line RS-F1 (Velge et al., 1995), chicken fibroblasts DF1 
TABLE 1 | Strains, plasmids and primers used in this study.

\begin{tabular}{|c|c|c|}
\hline Strains & Designation used in the article & References \\
\hline Salmonella Typhimurium 14028 & WT & ATCC \\
\hline $\begin{array}{l}\text { Salmonella Typhimurium } 14028 \\
\Delta \text { invA::kan } \Delta \text { pagN::cm } \Delta r c k\end{array}$ & STM-3 $\Delta$ & This study \\
\hline $\begin{array}{l}\text { Salmonella Typhimurium } 14028 \\
\text { AinvA::kan }\end{array}$ & STM- $\Delta$ invA & This study \\
\hline Escherichia coli MC1061 & E. coli MC1061 & Casadaban and Cohen, 1980 \\
\hline pGG2-DsRed & Plasmid carrying DsRed $\left(\mathrm{Cb}^{\mathrm{R}}\right)$ & Lelouard et al., 2010 \\
\hline pCX340 & Plasmid carrying $\beta$-lactamase gene $\left(\mathrm{Tc}^{\mathrm{R}}\right)$ & Fookes et al., 2011 \\
\hline pCX340sopD & Plasmid carrying sopD $\beta$-lactamase fusion $\left(\mathrm{Tc}^{\mathrm{R}}\right)$ & Fookes et al., 2011 \\
\hline pKD3 & Vector carrying an FRT-Cm-FRT cassette $\left(\mathrm{Cb}^{\mathrm{R}} \mathrm{Cm}^{\mathrm{R}}\right)$ & Datsenko and Wanner, 2000 \\
\hline pKD4 & Vector carrying an FRT-Kan-FRT cassette $\left(\mathrm{Cb}^{\mathrm{R}} \mathrm{Kan}^{\mathrm{R}}\right)$ & Datsenko and Wanner, 2000 \\
\hline rck-P2 & $\begin{array}{l}\text { 5'-CTCCGCTCCCTTCCTGCTCTCCGTTATCAGAACCGGTAACCGACACCAAC } \\
\text { ATATGAATATCCTCCTTAG-3' }\end{array}$ & This study \\
\hline P1-pagN & $\begin{array}{l}\text { 5'-GAAACTTGTCTITAGCCCAATATTAAGGCAGGTTCTGAAATGAAAAACTG } \\
\text { TGTAGGCTGGAGCTGCTTC-3' }\end{array}$ & This study \\
\hline P2-pagN & $\begin{array}{l}\text { 5'-CCTTCGGGAACCCACAGGACCAGCTATTTAACCGATAGTGTTAAAAAGGCCA } \\
\text { TATGAATATCCTCCTTAG-3' }\end{array}$ & This study \\
\hline P1-invA-TAA & $\begin{array}{l}\text { 5'-TTATATTGTIITATAACATTCACTGACTTGCTATCTGCTATCTCACCGAGTG } \\
\text { TAGGCTGGAGCTGCTTC-3' }\end{array}$ & This study \\
\hline P2-invA-GTG & $\begin{array}{l}\text { 5'-GTGCTGCTTCTCTACTTAACAGTGCTCGTTAACGACCTGAATTACTGATCATA } \\
\text { TGAATATCCTCCTTAG-3' }\end{array}$ & This study \\
\hline
\end{tabular}

(ATCC) and minipig male ileum finite cell line I31 (Kaeffer et al., 1993). Cells were routinely grown in $75 \mathrm{~cm}^{2}$ plastic tissue culture flasks at $37^{\circ} \mathrm{C}$ under $5 \% \mathrm{CO}_{2}$ in the different recommended cell culture media without antimicrobial compounds.

\section{Adhesion and Invasion Assays}

Gentamicin protection assays were performed as described previously (Roche et al., 2005). Briefly, the different steps of cell infection were analyzed with cells grown on 24-well tissue culture plates (Falcon) for 5 days to obtain subconfluent monolayers. Each experiment used two plates: one for the TCA step and the second for the invasion step. Cell monolayers were incubated in culture medium without antibiotics for $24 \mathrm{~h}$ and then infected for $1.5 \mathrm{~h}$ at $37^{\circ} \mathrm{C}$ with $10^{7} \mathrm{CFU}$ in $300 \mu \mathrm{L}$ in medium without serum (multiplicity of infection) MOI $=10$. For TCA assays, the cell monolayers were gently washed six times with phosphatebuffered saline (PBS) (pH 7.3) and then disrupted with $1 \mathrm{~mL}$ cold distilled water $\left(4^{\circ} \mathrm{C}\right)$. Viable bacteria (intra- and extracellular) were counted after plating serial dilutions on TSA. The other plates were washed with appropriate medium and incubated in culture medium containing $100 \mu \mathrm{g}$ of gentamicin per mL. After $1.5 \mathrm{~h}$ at $37^{\circ} \mathrm{C}$, cells were washed with PBS and lysed with $1 \mathrm{ml}$ cold distilled water $\left(4^{\circ} \mathrm{C}\right)$. Viable intracellular bacteria were assessed by serial dilutions plated on TSA (Tryptic Soy Agar-Difco).
Results were expressed as the mean \pm SEM of the number of intracellular bacteria for $10^{7} \mathrm{CFU}$. Experiments were performed in duplicate and repeated at least three times for each strain.

\section{Immunofluorescence}

AML-12 cells were seeded in 24-well plates with $12 \mathrm{~mm}$ diameter glass coverslips at $10^{5}$ cells per well, $24 \mathrm{~h}$ before infection. Bacteria expressing pGG2-DsRed were grown in TSB with the required antibiotic for $7-8 \mathrm{~h}$ at $37^{\circ} \mathrm{C}$ with shaking, diluted $1: 100$ in fresh TSB, and incubated overnight at $37^{\circ} \mathrm{C}$ without shaking. Bacteria were diluted 1:5 and absorbance was measured. Then bacteria were added to the cells at MOI $=100$ in medium without fetal calf serum. The infection was carried out for $1.5 \mathrm{~h}$ at $37^{\circ} \mathrm{C}$ in $5 \%$ $\mathrm{CO}_{2}$. Cells were washed four times with growth medium followed by twice with PBS and prepared for immunostaining.

Cells grown on coverslips were fixed with $3 \%$ formaldehyde $(\mathrm{pH} 7.4)$ in $\mathrm{PBS}$ at room temperature for $10 \mathrm{~min}$. Fixed cells were washed three times in PBS, extracellular bacteria were stained first with rabbit primary antibody (Salmonella Typhimurium Antibody, BIOSS Inc.) and then with secondary antibody (Donkey anti-Rabbit Alexa 488) diluted in PBS and incubated for $1 \mathrm{~h}$ at room temperature with three intermediary washes. Cells were permeabilized with $0.1 \%$ saponin in PBS and the cytoskeleton was stained using phalloidin Alexa 647 
at room temperature. Cell nuclei were stained with Dapi and coverslips were mounted on glass slides in Fluormount mounting medium. Cells were observed under a SP8 confocal laser-scanning microscope equipped with a $100 \times$ oil immersion objective (Leica). Images of 1,024 × 1,024 pixels were acquired using LaserX software (Leica). Sections $0.28 \mu \mathrm{m}$ thick (38 per image) were assembled into $\mathrm{Z}$ stacks using Las AF lite 2.6 .3 build 8173 software (Leica). Figure 2 shows one section representative of the $\mathrm{Z}$ stacks.

\section{Scanning-Electron Microscopy}

AML- 12 cells were seeded in 24-well plates with $12 \mathrm{~mm}$ diameter glass coverslips at $10^{6}$ cells per well $48 \mathrm{~h}$ before infection, and then infected with STM or STM-3 $\Delta$ at MOI $=100$ for 15, 30, $45,60,90,120$, or $150 \mathrm{~min}$. Cells were washed in PBS and fixed by incubation for $24 \mathrm{~h}$ in $4 \%$ paraformaldehyde, $1 \%$ glutaraldehyde in $0.1 \mathrm{M}$ phosphate buffer ( $\mathrm{pH}$ 7.2). Samples were then washed in PBS and post-fixed by incubation with $2 \%$ osmium tetroxide for $1 \mathrm{~h}$. Cells were then fully dehydrated in a graded series of ethanol solutions and dried in hexamethyldisilazane (HMDS, Sigma). Finally, samples were coated with 40 Å platinum, using a GATAN PECS 682 apparatus (Pleasanton, CA), before observation under a Zeiss Ultra plus FEG-SEM scanning-electron microscope (Oberkochen, Germany).

\section{Translocation Assay}

A $\beta$-lactamase (TEM-1) translocation assay of T3SS-1 effector proteins SopD was performed (Charpentier and Oswald, 2004). Briefly, S. Typhimurium14028 and invA mutant carrying SopD::TEM-1 fusions or controls without fusion were incubated for $1.5 \mathrm{~h}$ with AML-12 cells at MOI $=100$ in the presence of $1 \mathrm{mM}$ probenecid (Sigma). Following infection, cells were loaded with CCF4-AM $\beta$-lactamase substrate (LiveBLAzer FRET-B/G Loading Kit, Invitrogen) for $2 \mathrm{~h}$ and visualized for green and blue fluorescence using confocal microscopy. Translocation was detected with fluorescence microscopy (SP8 confocal microscope Leica) using fluorescent CCF4/AM. Green fluorescence indicates CCF4-AM loading and the presence of blue cells is evidence of TEM-effector fusion translocation.

\section{Macropinocytosis and Endocytosis Assays}

Invasion assays on an AML-12 cell line were performed in the presence of different inhibitors. AML-12 cells were pre-treated with drugs or their mock: amiloride (Sigma) at $1 \mathrm{mM}$ for $30 \mathrm{~min}$ in culture medium, chlorpromazine CPZ (Sigma) at $10 \mu \mathrm{g} / \mathrm{mL}$ for $1 \mathrm{~h}$ in culture medium, monodansylcadaverine MDC (Sigma) at $300 \mu \mathrm{M}$ for $1 \mathrm{~h}$ in DMSO, filipin (Sigma) at $5 \mu \mathrm{g} / \mathrm{mL}$ for $30 \mathrm{~min}$ in ethanol or genistein (Sigma) at $200 \mu \mathrm{M}$, for $30 \mathrm{~min}$ in DMSO. The dilution-effect of each drug was also performed. Viability of the bacteria was checked in the presence of all the dilutions of the drugs used. Bacteria (MOI = 10) diluted in the presence of the different drugs were deposited on cells for $1.5 \mathrm{~h}$. Gentamicin was added for $1.5 \mathrm{~h}$ (using the same procedure as for the cell invasion assays). The number of internalized bacteria was determined and expressed in relation to values obtained for cells treated with control-diluted reagent arbitrarily set at $100 \%$. Data are presented as the mean \pm SEM. in duplicate and were repeated at least twice for each strain.

\section{Statistical Analyses}

Asymptotic two-sample Fisher-Pitman permutation tests (OneWay-Test) were performed with the software $\mathrm{R}$, package $\mathrm{Rcmdr}$ version 2.3.1 (2016-10-25). Significance was ${ }^{* * * *}$ at $p<0.0001$, ${ }^{* * *} p<0.001,{ }^{* *} p<0.01,{ }^{*} p<0.05$ (http://www.r-project.org, http://socserv.socsci.mcmaster.ca/jfox/Misc/Rcmdr/).

\section{RESULTS}

\section{The Salmonella Typhimurium 14028 Strain Deleted for the Three Known Invasion Factors Remains Invasive in Several Eukaryotic Cell Lines}

Both S. Typhimurium 14028 and STM-3A strains were investigated with gentamicin protection assays conducted on different cell lines. Fibroblasts, epithelial and endothelial cells from human, chicken, mouse, pig and monkey origins were tested. Primary fibroblasts (mouse primary kidney cloned, termed finite cell line RS-F1, minipig male ileum finite cell line I31) were also added. The numbers of total cell-associated (TCA) wild-type bacteria and its mutant, which correspond to surface adherent and intracellular bacteria, were not significantly different (data not shown). In the gentamicin protection assay, the cell lines were classified according to their dependence or not of T3SS-1 for invasion (Figure 1). For the majority of the cell lines, the mutant had an invasion defect, highlighting the T3SS-1 dependent invasion process (i.e., from HT-29 to RS-F1). For other cell lines (i.e., chAEC, Caco-2, Ma104, AML-12, and IPEC-1), the wild-type and the triple mutant had an invasion rate between 4.4 and $6.5 \log \mathrm{CFU} /$ well, and with the mutant's invasion rate being only $0.5 \mathrm{log} C F U /$ well less than that of the wild-type strain. This result thus demonstrated that Salmonella remained able to enter some cells despite the absence of the three currently known invasion factors. However, no relation could be established according to the origin of the cells, as these results were obtained with four epithelial cell lines of different origins (Caco-2, Ma104, AML-12, and IPEC-1) and one endothelial cell line (chAEC). Moreover, no clear differences were observed between the primary cells and the cell lines. E. coli invasion was also checked in order to demonstrate that the uptake process observed by some cell types does not result from intrinsic ability to ingest bacteria independent of any virulence factors. Setting the uptake of the S. Typhimurium 14028 at $100 \%$, the uptake of the E.coli MC1061 were 0.58, 0.63, 0.11, 2.01, 0.22, 0.38 , respectively for AML-12, DF1, Ma104, HeLa, Huvec-p, and IPEC-1 cell lines.

\section{Significant T3SS-1 Independent Invasion Is Also Observed After a Brief Contact Between Bacteria and Cells}

T3SS-1 is known to mediate cell invasion as early as $15 \mathrm{~min}$ after bacteria/cell contact. To assess whether T3SS-1 independent invasion can also be seen early after bacteria/cell contact, we 


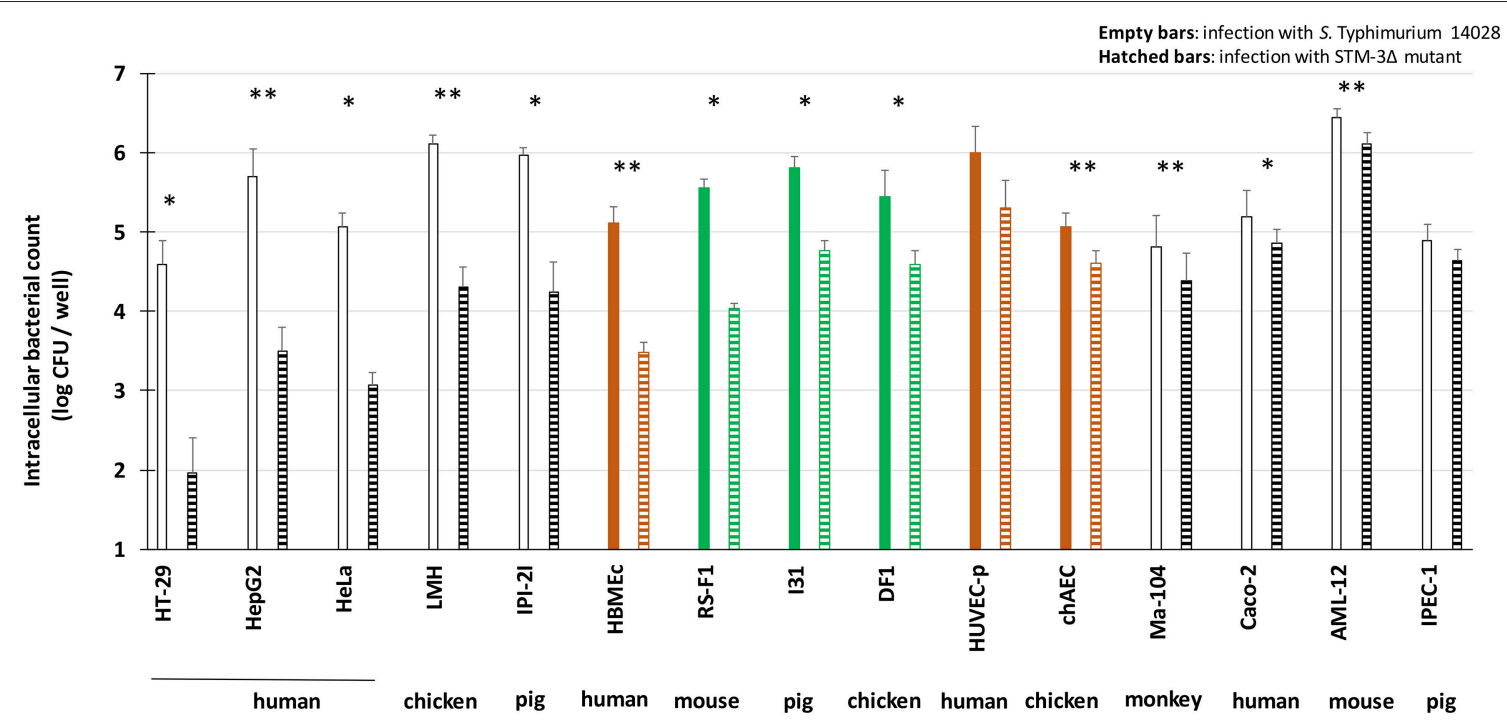

FIGURE 1 | S. Typhimurium 14028 inactivated for the three known invasion factors remains invasive for several eukaryotic cell lines. Invasion abilities of $S$. Typhimurium 14028 and the STM-3 $\Delta$ mutant were compared using gentamicin protection assays performed on different cell lines: epithelial cell lines (white bars), fibroblasts (green bars) and endothelial cell lines (brown bars). Bacteria (MOI = 10) were deposited on cells for $1.5 \mathrm{~h}$ followed by the addition of gentamicin $(100 \mu \mathrm{g} / \mathrm{mL})$ for $1.5 \mathrm{~h}$. Empty bars represent the number of intracellular wild-type bacteria. Hatched bars represent the number of intracellular mutant bacteria. The results correspond to the mean \pm SEM of at least three independent experiments performed in duplicate and expressed in log CFU/well. Cell lines were classified according to their dependence or not of T3SS-1 for invasion. Statistical analyses, using asymptomatic two-sample Fisher-Pitman permutation tests, were performed on intracellular bacterial counts between $S$. Typhimurium 14028 and STM-3 $\Delta$ mutant for each cell type. Significance was ${ }^{\star} P<0.05$ and ${ }^{*} P<0.01$.

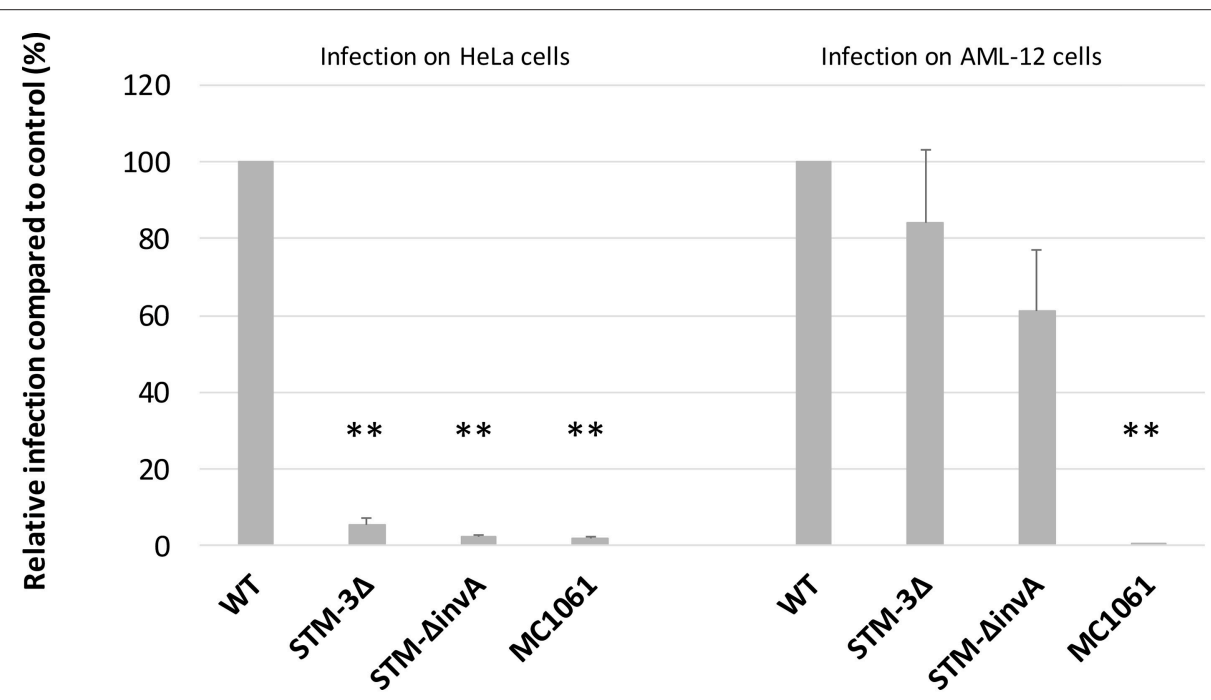

FIGURE 2 | Significant T3SS-1 independent invasion is also observed even after a short infection time. Gentamicin protection assays were performed on HeLa and AML-12 cells. Bacteria $(\mathrm{MOI}=10)$ were deposited on cells for $15 \mathrm{~min}$ followed by the addition of gentamicin $(100 \mu \mathrm{g} / \mathrm{mL})$ for $1.5 \mathrm{~h}$. Experiments were performed three times in duplicate and expressed as a percentage of relative infection. Data were analyzed using asymptotic two-sample Fisher-Pitman permutation tests. Significance was ${ }^{\star \star} P<0.01$. Statistical analyses also showed no significantly differences between the invasion rates of the STM-3 $\Delta$ and the STM- $\Delta i n v A$ mutants $(p=0.1969$ in the HeLa cells vs. $p=0.3514$ in the AML-12 cells).

performed a gentamicin protection assay on HeLa (a T3SS-1 dependent cell line) and AML-12 cells (a T3SS-1 independent cell line) with an infection time of 15 min instead of exposure for $1.5 \mathrm{~h}$ in 2.1. As a control, an invA mutant (T3SS-1 deficient) and a non-invasive E. coli (MC1061) strain were used. As expected, for HeLa cells, the Salmonella triple mutant and the invA mutant entered cells 19 and 40 times less than the wild-type strain, respectively. For AML-12 cells, the Salmonella triple mutant and the invA mutant entered cells 1.2 and 1.6 times less than the wildtype strain, respectively (Figure 2). These results showed that the 


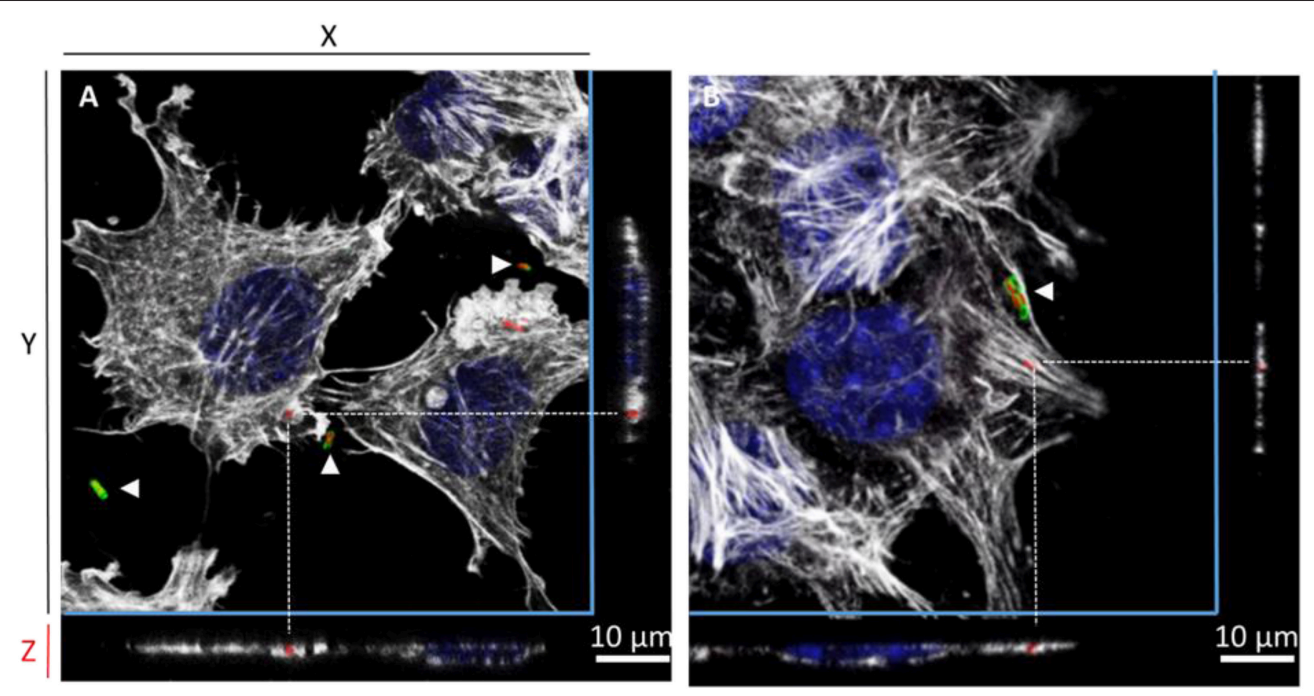

FIGURE 3 | Confocal microscopy reveals the intracellular location of $S$. Typhimurium inactivated for the three known invasion factors in AML-12 cells. One projection of Z-stack sections, obtained by confocal microscopy (Leica SP8), of AML-12 cells infected for $1.5 \mathrm{~h}$ at $37^{\circ} \mathrm{C}(\mathrm{MOI}=100)$ with either the $\mathrm{S}$. Typhimurium $14028(\mathbf{A})$ or the STM-3 $\Delta$ mutant (B) that expressed DsRed and were then processed by immunofluorescence. Intracellular bacteria were red due to DsRed expression or red and green (white arrowheads) when extracellular due to DsRed expression staining with a Salmonella O-antigen antibody revealed with goat anti-rabbit Alexa 488 (green) before permeabilization. Cell nuclei (DAPI) are shown in blue and actin in white (Phalloidin Alexa 647). Dotted lines indicate the position of intracellular bacteria in the Z-stack. Scale bar: $10 \mu \mathrm{m}$.


FIGURE 4 | Scanning electron microscopy reveals weak cell surface rearrangements assuming a zipper-like mechanism for both the $S$. Typhimurium wild-type and its triple mutant. Cells seeded on glass coverslips at $70 \%$ of confluence were infected with either the S. Typhimurium 14028 (A,B) or the STM-3 $\Delta$ mutant (C,D) at $\mathrm{MOI}=100$ then washed in PBS and processed for scanning-electron microscopy. Cells were then prepared for scanning electron microscopy. We selected representative observations of AML-12 cell surface rearrangements induced by S. Typhimurium 14028 and STM-3 $\Delta$ infection. They showed filipodia contact with Salmonella (A-60 min and C-90 min) with weak membrane invagination surrounding Salmonella and engulfment (B-150 min and $\mathbf{D}-150 \mathrm{~min})$. Bars: $1 \mu \mathrm{m}$. 

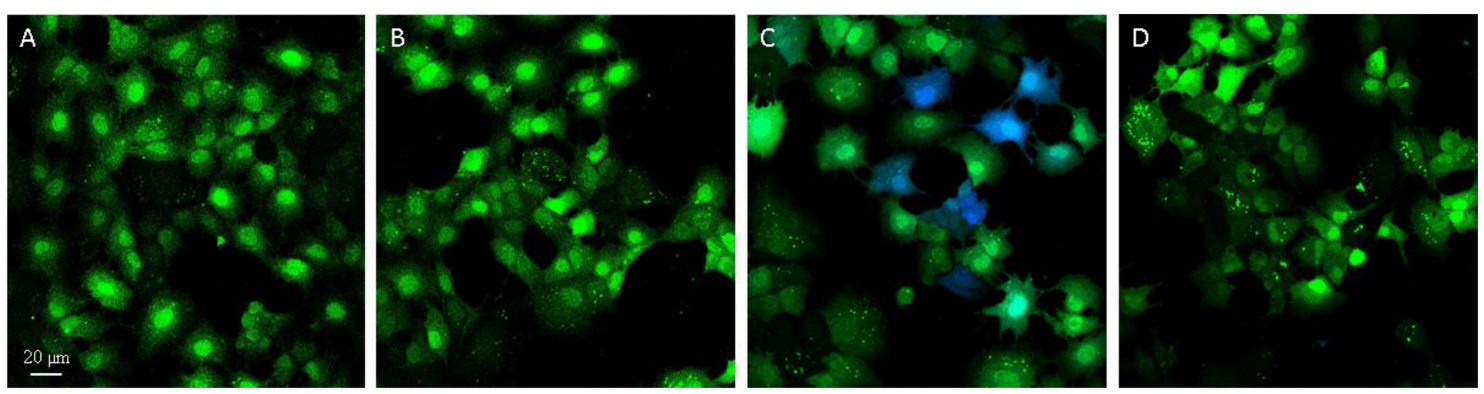

FIGURE 5 | The T3SS-1 apparatus of the S. Typhimurium 14028 strain is functional in AML-12 cells. S. Typhimurium 14028 or $\Delta$ invA expressing SopD effector-TEM-1 $\beta$-lactamase were used to infect AML-12 cells for $1.5 \mathrm{~h}$. Following infection, cells were loaded with CCF4-AM for $2 \mathrm{~h}$ and visualized for green or blue fluorescence through microscopy. Green fluorescence indicates that CCF4-AM was loaded and the presence of blue cells due to cleaved CCF4-AM revealed translocation. AML-12 cells were non-infected (A), or infected with S. Typhimurium 14028 carrying the empty vector pCX340 (B), S. Typhimurium 14028 expressing SopD effector-TEM-1 in pCX340 (C) and STM- $\triangle$ invA expressing SopD effector-TEM-1 in pCX340 (D)

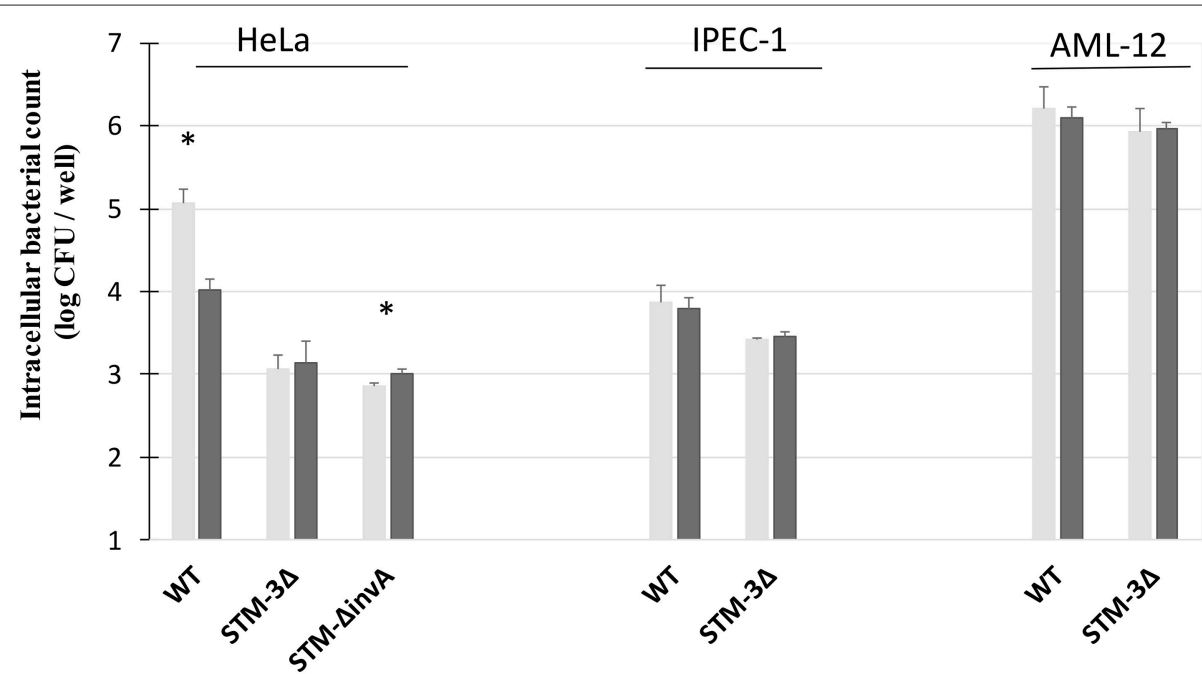

FIGURE 6 | Amiloride affected the invasion of S. Typhimurium 14028 strain in HeLa cells T3SS-1 dependent-invasion. Invasion abilities of the S. Typhimurium 14028 and STM-3 $\Delta$ mutant were compared using gentamicin protection assays performed on HeLa cells, AML-12 cells and IPEC-1 cells in the presence or not of amiloride. On HeLa monolayers, the single mutant 1 invA was added as a control. Cells were pre-treated with amiloride (1 mM) (black bars) or the culture medium (gray bars) for $30 \mathrm{~min}$. Bacteria $(\mathrm{MOI}=10)$ were deposited on cells for $1.5 \mathrm{~h}$ followed by the addition of gentamicin $(100 \mu \mathrm{g} / \mathrm{mL})$ for $1.5 \mathrm{~h}$. The numbers of internalized bacteria were determined. Data are the mean \pm SEM in duplicate and repeated at least twice for each strain. Statistical analyses, using asymptomatic two-sample Fisher-Pitman permutation tests, were performed on intracellular bacterial counts between the infection in presence of culture medium (gray) or amiloride (black). Significance was ${ }^{\star} P<0.05$.

T3SS-1-independent invasion of Salmonella into AML-12 cells occurs even after a short contact time, known to be sufficient for T3SS-1 invasion (Steele-Mortimer et al., 2002). Additionally, these data demonstrated that the entry of Salmonella into AML12 cells was specific, since an E. coli strain entered this cell line at only a very low level.

\section{Microscopy Reveals the Uptake of the S. Typhimurium 14028 Strain Inactivated for the Three Known Invasion Factors by AML-12 Cells}

The gentamicin protection assays revealed that the triple mutant entered AML-12 cells at a level close to that of the wildtype strain. Further experiments using confocal microscopy were thus carried out to confirm the intracellular localization of the wild-type and the STM-3 $\Delta$ mutant. After verifying that no differences could be observed in the invasion rates between bacteria carrying or not pGG2-DsRed expressing DsRed (S. Typhimurium and STM-3 $\Delta$ ) (6.17/6.11 log CFU for the wild-type and 6.17/5.95 log CFU for the STM-3 $\Delta$ ), $70 \%$ confluent monolayers were infected for confocal microscope imaging. Intracellular S. Typhimurium expressing DsRed were visualized only red. Extracellular bacteria (adherent and free) labeled with a rabbit antibody directed against Salmonella and revealed with a green secondary antibody, were observed in red and green. Intracellular bacteria (in red) were observed and Z-stack acquisitions showed that they were embedded in white actin cocoons revealed by phalloidin staining (Figure 3 ). The recruitment of actin may reflect different levels of cell membrane 




rearrangement. As extensive or low cell rearrangement leads to trigger- or a zipper-like entry mechanism, respectively and as confocal imaging did not enable identification of the process involved, we next examined the morphological alterations occurring in AML-12 cells during bacterial uptake under a scanning-electron microscope (Figure 4). AML-12 cells tended to produce filipodia that came into contact with bacteria. Weak rearrangements were observed with cell invagination or bacteria wrapping, as already described in cells deficient in WAVE-complex function (Hänisch et al., 2010). These observations correspond to a zipper-like entry mechanism. Surprisingly, we did not observe any prominent membrane ruffles, the hallmark of the trigger mechanism, either with the wild-type bacteria (Figures 4A,B) or less surprising with the STM-3 $\Delta$ mutant (Figures 4C,D). To ensure that these results were not time dependent, similar observations were conducted at different post-infection times $(15,30,45,60,90,120$, and $150 \mathrm{~min}$ ) (data not shown). 


\section{Despite a Zipper-Like Invasion, the T3SS-1 Apparatus of the S. Typhimurium 14028 Strain Is Functional in AML-12 Cells}

As a zipper-like invasion was observed with the wild-type strain, we investigated whether this strain was able to translocate T3SS-1 effectors into the host cell cytosol and thus whether its T3SS1 apparatus was functional in AML-12 cells. For that purpose, we performed a fluorescence-based translocation assay using a fusion protein of the SopD effector with mature TEM-1 $\beta$-lactamase and fluorescent $\beta$-lactamase substrate CCF4-AM. The emission of blue fluorescence by AML-12 cells previously loaded with the substrate reveals cleavage of the CCF4-AM substrate by $\beta$-lactamase and therefore translocation of SopD into these cells. Uncleaved CCF4-AM emits green fluorescence. Blue cells were observed when AML-12 cells were infected with the wild-type strain carrying pCX340-sopD, the plasmid encoding SopD-TEM-1, demonstrating that $S$. Typhimurium 14028 was able to translocate the fusion protein into the host cell cytosol (Figure 5). In contrast, cells infected with the same strain carrying the empty vector pCX340 only emitted green fluorescence, indicating that conversion of the fluorescence of CCF4-AM (blue cells) was only due to the presence of the fusion protein in the host cell. This translocation was T3SS-1dependent since the $\triangle i n v A$ mutant, which is unable to assemble a functional T3SS- 1 and thus to inject T3SS-1 effectors, did not induce blue cells even when carrying the pCX340-sopD plasmid. These data demonstrate that $S$. Typhimurium 14028 was able to translocate at least the SopD T3SS-1 effector into the AML12 cytosol indicating that the T3SS- 1 was functional during the interaction of $S$. Typhimurium 14028 with AML-12 cells.

\section{Both Clathrin- and Non-clathrin-Dependent Pathways Are Used by a S. Typhimurium Mutant Inactivated for the Three Known Invasion Factors}

Previous results showed that $S$. Typhimurium 14028 had a functional T3SS-1. However, no trigger invasion images were observed using scanning-electron microscopy.

To determine the pathways involved in the entry of the S. Typhimurium 14028 or the STM-3 $\Delta$, we tested chemical inhibitors that are commonly used to target macropinocytosis [amiloride (Koivusalo et al., 2010)], clathrin-mediated endocytosis [monodansylcadaverine, MDC Schlegel et al., 1982 and chlorpromazine, CPZ Wang et al., 1993], and the clathrin-independent, but lipid-raft-dependent route (filipin and genistein; Rejman et al., 2005).

Previous studies showed that $S$. Typhimurium was internalized through macropinocytosis (Alpuche-Aranda et al., 1994; Rosales-Reyes et al., 2012) or that bacteria were associated with macropinocytosic vacuoles (Garcia-Del Portillo and Finlay, 1994). The effect of amiloride was tested on HeLa cells, a T3SS-1 dependent-invasion cell line (Figure 6). A factor of invasion was calculated in presence of amiloride or not. In accordance with previous papers, we observed that amiloride inhibited the entry of the wild-type bacteria. Indeed the wild-type bacteria entered 11.70 times better in absence of
TABLE 2 | Statistical analysis comparing the invasion rates of the wild-type strain and the STM-3 $\Delta$ mutant, in the presence of drugs according to asymptotic two-sample Fisher-Pitman permutation tests (One-Way-Test) with the software R, package Rcmdr version 2.3.1 (2016-10-25).

\begin{tabular}{|c|c|c|c|c|c|}
\hline & $\begin{array}{l}\text { CPZ } \\
\text { (p-values) }\end{array}$ & $\begin{array}{c}\text { MDC } \\
\text { (p-values) }\end{array}$ & $\begin{array}{c}\text { Filipin } \\
\text { (p-values) }\end{array}$ & $\begin{array}{l}\text { Genistein } \\
\text { (p-values) }\end{array}$ & $\begin{array}{l}\text { CPZ-filipin } \\
\text { (p-values) }\end{array}$ \\
\hline Pure & $0.006573^{\star *}$ & $0.01267^{\star}$ & 0.3795 & $0.03427^{*}$ & \\
\hline Dilution 1/10 & $0.02669^{*}$ & 0.05497 & 0.1263 & 0.05884 & \\
\hline Dilution 1/100 & 0.3697 & 0.9171 & 0.293 & 0.5316 & 0.5712 \\
\hline Dilution 1/1,000 & 0.7431 & 0.2107 & 0.7901 & 0.2694 & \\
\hline
\end{tabular}

Significance was at ${ }^{\star \star} p<0.01,{ }^{*} p<0.05$ (http://www.r-project.org, $h$ ttp://socserv.socsci. mcmaster.ca/jfox/Misc/Rcmdr/).

amiloride. By contrast, the entries of the single mutant $\Delta i n v A$ and the STM-3 3 were not altered in absence or presence of amiloride (factor $0.79,0.72$, respectively). These results reflect a T3SS-1 dependent-invasion process in HeLa cells. On the other hand, with AML-12 cells, amiloride did not affect the entry of the bacteria tested, and there were no significant differences between the wild-type and the triple mutant (factor 0.96, 1.00, respectively). To evaluate whether this phenomenon was specific to the cell line or to the invasion process, we tested amiloride on the IPEC-1 cell line, mediating another potential T3SS-1-, Rck-, PagN-independent-invasion process. Similarly, amiloride treatment had no effect on the entry of the wild-type or the STM-3 $\Delta$ mutant (factor $1.22,0.91$, respectively) suggesting that the invasion process in these two cellular models was not related to macropinocytosis.

For all the chemical compounds whatever the concentrations tested, the integrity of the cell monolayers was not affected. Further analyses showed that all drugs affecting the clathrinand the non-clathrin-dependent pathways had an inhibitory and dose-dependent effect on S. Typhimurium 14028 and STM-3 $\Delta$ invasion (Figures 7A,B). These findings combined with the fact that we could totally inhibit invasion, suggest that both pathways had a significant role in the entry of the wild-type strain and its isogenic mutant. As the drugs decreased the entry-rates of the bacteria to a similar extent, we decided to associate two different drugs, CPZ and filipin at a dose inhibiting $50 \%$ of the entry to demonstrate a cumulative or a redundant pathway. A cumulative effect would favor the existence of two distinct pathways. As no cumulative effect was observed, our result suggests that CPZ and filipin target the same internalization pathway. Moreover, when we compared the invasion rates of the wild-type bacteria and its mutant, no significant differences were obtained in their responses to the different drugs (Table 2) suggesting that both strains used the same entry process.

\section{DISCUSSION}

Salmonella Typhimurium invasion, and particularly the role of the T3SS-1, has been extensively characterized in cultured epithelial cells. This invasion process involves a subset of T3SS-1 effectors (SipA, SipC, SopB, SopE, SopE2) acting in concert to induce massive localized rearrangements of actin at the 
plasma membrane level, and also to activate signaling pathways resulting in membrane ruffling and macropinocytosis at the site of Salmonella-epithelial cell contact (Mcghie et al., 2009; Aiastui et al., 2010; Dunn and Valdivia, 2010). This entry process refers to a trigger entry mechanism. Moreover, Rosselin et al. demonstrated that Rck-coated beads and E. coli expressing Rck were able to induce a weak membrane rearrangement named the zipper mechanism in different cell lines (Rosselin et al., 2010). Consequently, a new paradigm has emerged based on the multiplicity of Salmonella entry mechanisms (Velge et al., 2012).

Our work provides some arguments supporting this new paradigm. A Salmonella triple mutant inactivated for the three known invasion factors, i.e., the T3SS-1 and the Rck and PagN invasins, is able to invade several cell lines at levels close to the wild-type strain, highlighting that uncharacterized invasion factors remain to be identified. However, this is not related to the cell origin (human, mouse, chicken, pig, and monkey) or the cell type (e.g., primary, epithelial, or endothelial cell lines). Our results also demonstrated that $S$. Typhimurium is able to invade some epithelial cells, according to a zipper-like mechanism, despite a functional T3SS-1. This observation is reinforced by the fact that macropinocytosis seemed not to be essential, as amiloride did not affect the invasion of two epithelial cell lines.

We also showed that the STM-3A mutant used the same entry pathway. In our model, the wild-type as well as the STM-3 $\Delta$ mutant entered through a pathway involving both clathrin- and non-clathrin-dependent pathways. Veiga et al. demonstrated that bacteria injecting effectors into the host cells through a T3SS entered independently of a clathrin-dependent endocytic machinery, in contrast to the process observed for the entry of zippering pathogens (Veiga et al., 2007). However, this finding is not clear cut. First, their work was performed on a T3SS-1 dependent cell model and thus, depending on the cell used, either T3SS-1 dependent or independent, different entry pathways could be involved. In line with this, Cossart et al. showed that Listeria, which enters through a zipper mechanism, used both clathrin- and non-clathrin-dependent pathways (Cossart and Helenius, 2014). In the present study, we observed that the highest dose of chlorpromazine or filipin tested almost abolished Salmonella invasion to close to $100 \%$ suggesting that one endocytosis process was not compensated by another. These observations might indicate shared actors between the two endocytosis pathways or a partial specificity of the drugs used.

\section{REFERENCES}

Abed, N., Grépinet, O., Canepa, S., Hurtado-Escobar, G. A., Guichard, N., Wiedemann, A., et al. (2014). Direct regulation of the pefI-srgC operon encoding the Rck invasin by the quorum-sensing regulator SdiA in Salmonella Typhimurium. Mol. Microbiol. 94, 254-271. doi: 10.1111/mmi. 12738

Aiastui, A., Pucciarelli, M. G., and García-del Portillo, F. (2010). Salmonella enterica serovar Typhimurium invades fibroblasts by multiple routes differing from the entry into epithelial cells. Infect. Immun. 78, 2700-2713. doi: 10.1128/IAI.01389-09
Our results showing that the wild-type strain did not use its T3SS-1 to enter cells despite a functional apparatus, demonstrate that the T3SS-1 is not required to infect some host cells. To date, most cell lines that have been used to study Salmonella invasion, (such as HeLa or HT-29 cells) are T3SS-1 dependent (Radtke et al., 2010). This could explain why invasion factors other than the T3SS-1 have not been identified easily. Recently however, other studies have shown that some mutants with their invasion altered, remained virulent in vitro and in vivo. For example, a mutant strain lacking the T3SS-1 effectors SopE and SopE2 was still able to invade fibroblast-like COS-7 cells in the absence of membrane ruffling (Stender et al., 2000). Similarly, a $S$. Enteritidis strain deleted for invA, not expressing Rck or PagN, was still able to invade fibroblast, epithelial and endothelial cells significantly using a zipper-like mechanism (Rosselin et al., 2011). Moreover, a $S$. Typhimurium $\Delta$ SPI-1 mutant entered rat and mouse fibroblasts (Aiastui et al., 2010), and S. Typhimurium mutants lacking the invA and $\operatorname{sip} B$ genes could infect human brain microvascular endothelial cells (Van Sorge et al., 2011).

In conclusion, Salmonella invasion of non-phagocytic cells is more complex than previously thought. Why the $S$. Typhimurium wild-type did not use its T3SS-1 to enter some cell lines is of fundamental importance and raises the question of the mechanisms that govern the initial steps of the invasion processes. How does the intracellular behavior of the bacteria change according to the entry factor used? Are the different entry processes involved in tissue tropism, host specificity and/ or disease outcome? Is there a synergy between the different entry mechanisms? The identification of the new invasion factors and the subsequent characterization of their entry mechanisms will undoubtedly help us to answer these questions.

\section{AUTHOR CONTRIBUTIONS}

SR, SH, IV-P, and PV contributed to the conception and design of this study. SR, SH, SS, SG, and JT performed the experiments. $\mathrm{SR}$ and $\mathrm{SH}$ analyzed the data and wrote the manuscript. IV-P and $\mathrm{PV}$ discussed the results and improved the manuscript.

\section{ACKNOWLEDGMENTS}

We thank P. Quéré and E. Esnault for their technical support in the culture of the chAEC cell line (UMR ISP, INRA Centre Val de Loire, France).
Alpuche-Aranda, C. M., Racoosin, E. L., Swanson, J. A., and Miller, S. I. (1994). Salmonella stimulate macrophage macropinocytosis and persist within spacious phagosomes. J. Exp. Med. 179, 601-608. doi: 10.1084/jem.179.2.601

Casadaban, M. J., and Cohen, S. N. (1980). Analysis of gene control signals by DNA fusion and cloning in Escherichia coli. J. Mol. Biol. 138, 179-207. doi: 10.1016/0022-2836(80)90283-1

Charpentier, X., and Oswald, E. (2004). Identification of the secretion and translocation domain of the enteropathogenic and enterohemorrhagic Escherichia coli effector Cif, using TEM-1 beta-lactamase as a new fluorescence-based reporter. J. Bacteriol. 186, 5486-5495. doi: 10.1128/JB.186.16.5486-5495.2004 
Cherepanov, P. P., and Wackernagel, W. (1995). Gene disruption in Escherichia coli: $\mathrm{TcR}$ and $\mathrm{KmR}$ cassettes with the option of Flp-catalyzed excision of the antibiotic-resistance determinant. Gene 158, 9-14. doi: 10.1016/0378-1119(95)00193-A

Cossart, P., and Helenius, A. (2014). Endocytosis of viruses and bacteria. Cold Spring Harb. Perspect. Biol. 6:a016972. doi: 10.1101/cshperspect.a016972

Datsenko, K. A., and Wanner, B. L. (2000). One-step inactivation of chromosomal genes in Escherichia coli K-12 using PCR products. Proc. Natl. Acad. Sci. U.S.A. 97, 6640-6645. doi: 10.1073/pnas.120163297

De Jong, H. K., Parry, C. M., Van Der Poll, T., and Wiersinga, W. J. (2012). Host-pathogen interaction in invasive Salmonellosis. PLoS Pathog. 8:e1002933. doi: 10.1371/journal.ppat.1002933

Desin, T. S., Lam, P. K., Koch, B., Mickael, C., Berberov, E., Wisner, A. L., et al. (2009). Salmonella enterica serovar Enteritidis pathogenicity island 1 is not essential for but facilitates rapid systemic spread in chickens. Infect. Immun. 77, 2866-2875. doi: 10.1128/IAI.00039-09

Dunn, J. D., and Valdivia, R. H. (2010). Uncivil engineers: Chlamydia, Salmonella and Shigella alter cytoskeleton architecture to invade epithelial cells. Future Microbiol. 5, 1219-1232. doi: 10.2217/fmb.10.77

EFSA. (2017). The European Union summary report on trends and sources of zoonoses, zoonotic agents and food-borne outbreaks in 2016. EFSA J. 15, 5077. doi: $10.2903 /$ j.efsa.2017.5077

Finlay, B. B., and Brumell, J. H. (2000). Salmonella interactions with host cells: in vitro to in vivo. Philos. Trans. R. Soc. Lond. B Biol. Sci. 355, 623-631. doi: 10.1098/rstb.2000.0603

Fookes, M., Schroeder, G. N., Langridge, G. C., Blondel, C. J., Mammina, C., Connor, T. R., et al. (2011). Salmonella bongori provides insights into the evolution of the Salmonellae. PLoS Pathog. 7:e1002191. doi: 10.1371/journal.ppat.1002191

Francis, C. L., Starnbach, M. N., and Falkow, S. (1992). Morphological and cytoskeletal changes in epithelial cells occur immediately upon interaction with Salmonella Typhimurium grown under low-oxygen conditions. Mol. Microbiol. 6, 3077-3087. doi: 10.1111/j.1365-2958.1992.tb0 1765. $\mathrm{x}$

Garcia-Del Portillo, F., and Finlay, B. B. (1994). Salmonella invasion of nonphagocytic cells induces formation of macropinosomes in the host cell. Infect. Immun. 62, 4641-4645.

Gonzalez-Vallina, R., Wang, H., Zhan, R., Berschneider, H. M., Lee, R. M., Davidson, N. O., et al. (1996). Lipoprotein and apolipoprotein secretion by a newborn piglet intestinal cell line (IPEC-1). Am. J. Physiol. 271, G249-G259. doi: 10.1152/ajpgi.1996.271.2.G249

Hänisch, J., Ehinger, J., Ladwein, M., Rohde, M., Derivery, E., Bosse, T., et al. (2010). Molecular dissection of Salmonella-induced membrane ruffling versus invasion. Cell Microbiol. 12, 84-98. doi: 10.1111/j.1462-5822.2009.01380.x

Hänisch, J., Stradal, T. E., and Rottner, K. (2012). A novel contractility pathway operating in Salmonella invasion. Virulence 3, 81-86. doi: 10.4161/viru.3.1.18454

Hapfelmeier, S., Stecher, B., Barthel, M., Kremer, M., Müller, A. J., Heikenwalder, M., et al. (2005). The Salmonella pathogenicity island (SPI)-2 and SPI-1 type III secretion systems allow Salmonella serovar Typhimurium to trigger colitis via MyD88-dependent and MyD88-independent mechanisms. J. Immunol. 174, 1675-1685. doi: 10.4049/jimmunol.174.3.1675

Heffernan, E. J., Wu, L., Louie, J., Okamoto, S., Fierer, J., and Guiney, D. G. (1994). Specificity of the complement resistance and cell association phenotypes encoded by the outer membrane protein genes rck from Salmonella Typhimurium and ail from Yersinia enterocolitica. Infect. Immun. 62, 5183-5186.

Heithoff, D. M., Conner, C. P., Hentschel, U., Govantes, F., Hanna, P. C., and Mahan, M. J. (1999). Coordinate intracellular expression of Salmonella genes induced during infection. J. Bacteriol. 181, 799-807.

Kaeffer, B., Bottreau, E., Velge, P., and Pardon, P. (1993). Epithelioid and fibroblastic cell lines derived from the ileum of an adult histocompatible miniature boar (d/d haplotype) and immortalized by SV40 plasmid. Eur. J. Cell Biol. 62, 152-162.

Koivusalo, M., Welch, C., Hayashi, H., Scott, C. C., Kim, M., Alexander, T., et al. (2010). Amiloride inhibits macropinocytosis by lowering submembranous $\mathrm{pH}$ and preventing Rac1 and Cdc42 signaling. J. Cell Biol. 188, 547-563. doi: $10.1083 /$ jcb.20090808620100331c
Lambert, M. A., and Smith, S. G. (2008). The PagN protein of Salmonella enterica serovar Typhimurium is an adhesin and invasin. BMC Microbiol. 8:142. doi: 10.1186/1471-2180-8-142

Lambert, M. A., and Smith, S. G. (2009). The PagN protein mediates invasion via interaction with proteoglycan. FEMS Microbiol. Lett. 297, 209-216. doi: 10.1111/j.1574-6968.2009.01666.x

Lelouard, H., Henri, S., De Bovis, B., Mugnier, B., Chollat-Namy, A., Malissen, B., et al. (2010). Pathogenic bacteria and dead cells are internalized by a unique subset of Peyer's patch dendritic cells that express lysozyme. Gastroenterology 138, 173-184 e171-173. doi: 10.1053/j.gastro.2009.09.051

Le Roy, C., and Wrana, J. L. (2005). Clathrin- and non-clathrin-mediated endocytic regulation of cell signalling. Nat. Rev. Mol. Cell Biol. 6, 112-126. doi: $10.1038 / \mathrm{nrm} 1571$

Lion, A., Richard, M., Esnault, E., Kut, E., Soubieux, D., Guillory, V., et al. (2017). Productive replication of avian influenza viruses in chicken endothelial cells is determined by hemagglutinin cleavability and is related to innate immune escape. Virology 513, 29-42. doi: 10.1016/j.virol.2017.10.007

Ly, K. T., and Casanova, J. E. (2007). Mechanisms of Salmonella entry into host cells. Cell Microbiol. 9, 2103-2111. doi: 10.1111/j.1462-5822.2007.00992.x

Maréchal, V., Prevost, M. C., Petit, C., Perret, E., Heard, J. M., and Schwartz, O. (2001). Human immunodeficiency virus type 1 entry into macrophages mediated by macropinocytosis. J. Virol. 75, 11166-11177. doi: 10.1128/JVI.75.22.11166-11177.2001

Mayor, S., Parton, R. G., and Donaldson, J. G. (2014). Clathrin-independent pathways of endocytosis. Cold Spring Harb. Perspect. Biol. 6:a016758. doi: 10.1101/cshperspect.a016758

Mcghie, E. J., Brawn, L. C., Hume, P. J., Humphreys, D., and Koronakis, V. (2009). Salmonella takes control: effector-driven manipulation of the host. Curr. Opin. Microbiol. 12, 117-124. doi: 10.1016/j.mib.2008.12.001

Mcmahon, H. T., and Boucrot, E. (2011). Molecular mechanism and physiological functions of clathrin-mediated endocytosis. Nat. Rev. Mol. Cell Biol. 12, 517-533. doi: 10.1038/nrm3151

Murray, R. A., and Lee, C. A. (2000). Invasion genes are not required for Salmonella enterica serovar Typhimurium to breach the intestinal epithelium: evidence that salmonella pathogenicity island 1 has alternative functions during infection. Infect. Immunol. 68, 5050-5055. doi: 10.1128/IAI.68.9.5050-5055.2000

Parton, R. G., and Richards, A. A. (2003). Lipid rafts and caveolae as portals for endocytosis: new insights and common mechanisms. Traffic 4, 724-738. doi: $10.1034 / j .1600-0854.2003 .00128 . x$

Radtke, A. L., Wilson, J. W., Sarker, S., and Nickerson, C. A. (2010). Analysis of interactions of Salmonella type three secretion mutants with 3-D intestinal epithelial cells. PLoS ONE 5:e15750. doi: 10.1371/journal.pone.0015750

Rejman, J., Bragonzi, A., and Conese, M. (2005). Role of clathrin- and caveolaemediated endocytosis in gene transfer mediated by lipo- and polyplexes. Mol. Ther. 12, 468-474. doi: 10.1016/j.ymthe.2005.03.038

Roche, S. M., Gracieux, P., Milohanic, E., Albert, I., Virlogeux-Payant, I., Témoin, S., et al. (2005). Investigation of specific substitutions in virulence genes characterizing phenotypic groups of low-virulence field strains of Listeria monocytogenes. Appl. Environ. Microbiol. 71, 6039-6048. doi: 10.1128/AEM.71.10.6039-6048.2005

Rosales-Reyes, R., Perez-Lopez, A., Sanchez-Gomez, C., Hernandez-Mote, R. R., Castro-Eguiluz, D., Ortiz-Navarrete, V., et al. (2012). Salmonella infects B cells by macropinocytosis and formation of spacious phagosomes but does not induce pyroptosis in favor of its survival. Microb. Pathog. 52, 367-374. doi: 10.1016/j.micpath.2012.03.007

Rosselin, M., Abed, N., Virlogeux-Payant, I., Bottreau, E., Sizaret, P. Y., Velge, P., et al. (2011). Heterogeneity of type III secretion system (T3SS)-1-independent entry mechanisms used by Salmonella Enteritidis to invade different cell types. Microbiology 157, 839-847. doi: 10.1099/mic.0.044941-0

Rosselin, M., Virlogeux-Payant, I., Roy, C., Bottreau, E., Sizaret, P. Y., Mijouin, L., et al. (2010). Rck of Salmonella enterica, subspecies enterica serovar Enteritidis, mediates zipper-like internalization. Cell Res. 20, 647-664. doi: $10.1038 /$ cr. 2010.45

Santos, R. L., Zhang, S., Tsolis, R. M., Kingsley, R. A., Adams, L. G., and Bäumler, A. J. (2001). Animal models of Salmonella infections: enteritis versus typhoid fever. Microbes Infect. 3, 1335-1344. doi: 10.1016/S1286-4579(01) 01495-2 
Schlegel, R., Dickson, R. B., Willingham, M. C., and Pastan, I. H. (1982). Amantadine and dansylcadaverine inhibit vesicular stomatitis virus uptake and receptor-mediated endocytosis of alpha 2-macroglobulin. Proc. Natl. Acad. Sci. U.S.A. 79, 2291-2295. doi: 10.1073/pnas.79.7.2291

Sigismund, S., Confalonieri, S., Ciliberto, A., Polo, S., Scita, G., and Di Fiore, P. P. (2012). Endocytosis and signaling: cell logistics shape the eukaryotic cell plan. Physiol. Rev. 92, 273-366. doi: 10.1152/physrev.00005.2011

Steele-Mortimer, O., Brumell, J. H., Knodler, L. A., Méresse, S., Lopez, A., and Finlay, B. B. (2002). The invasion-associated type III secretion system of Salmonella enterica serovar Typhimurium is necessary for intracellular proliferation and vacuole biogenesis in epithelial cells. Cell Microbiol. 4, 43-54. doi: 10.1046/j.1462-5822.2002.00170.x

Stender, S., Friebel, A., Linder, S., Rohde, M., Mirold, S., and Hardt, W. D. (2000). Identification of SopE2 from Salmonella Typhimurium, a conserved guanine nucleotide exchange factor for Cdc42 of the host cell. Mol. Microbiol. 36, 1206-1221. doi: 10.1046/j.1365-2958.2000.01933.x

Van Cauteren, D., Le Strat, Y., Sommen, C., Bruyand, M., Tourdjman, M., Da Silva, N. J., et al. (2017). Estimated annual numbers of foodborne pathogenassociated illnesses, hospitalizations, and deaths, France, 2008-2013. Emerg. Infect. Dis. 23, 1486-1492. doi: 10.3201/eid2309.170081

Van Sorge, N. M., Zialcita, P. A., Browne, S. H., Quach, D., Guiney, D. G., and Doran, K. S. (2011). Penetration and activation of brain endothelium by Salmonella enterica serovar Typhimurium. J. Infect. Dis. 203, 401-405. doi: 10.1093/infdis/jiq048

Veiga, E., Guttman, J. A., Bonazzi, M., Boucrot, E., Toledo-Arana, A., Lin, A. E., et al. (2007). Invasive and adherent bacterial pathogens co-Opt host clathrin for infection. Cell Host Microbe 2, 340-351. doi: 10.1016/j.chom.2007. 10.001
Velge, P., Kaeffer, B., Bottreau, E., and Van Langendonck, N. (1995). The loss of contact inhibition and anchorage-dependent growth are key steps in the acquisition of Listeria monocytogenes susceptibility phenotype by nonphagocytic cells. Biol. Cell 85, 55-66. doi: 10.1111/j.1768-322X.1995.tb00942.x

Velge, P., Wiedemann, A., Rosselin, M., Abed, N., Boumart, Z., Chaussé, A. M., et al. (2012). Multiplicity of Salmonella entry mechanisms, a new paradigm for Salmonella pathogenesis. Microbiologyopen 1, 243-258. doi: 10.1002/mbo3.28

Wang, L. H., Rothberg, K. G., and Anderson, R. G. (1993). Mis-assembly of clathrin lattices on endosomes reveals a regulatory switch for coated pit formation. $J$. Cell Biol. 123, 1107-1117. doi: 10.1083/jcb.123.5.1107

Wiedemann, A., Mijouin, L., Ayoub, M. A., Barilleau, E., Canepa, S., TeixeiraGomes, A. P., et al. (2016). Identification of the epidermal growth factor receptor as the receptor for Salmonella Rck-dependent invasion. FASEB J. 30, 4180-4191. doi: 10.1096/fj.201600701R

Conflict of Interest Statement: The authors declare that the research was conducted in the absence of any commercial or financial relationships that could be construed as a potential conflict of interest.

The reviewer BA and handling Editor declared their shared affiliation.

Copyright (c) 2018 Roche, Holbert, Trotereau, Schaeffer, Georgeault, VirlogeuxPayant and Velge. This is an open-access article distributed under the terms of the Creative Commons Attribution License (CC BY). The use, distribution or reproduction in other forums is permitted, provided the original author $(s)$ and the copyright owner(s) are credited and that the original publication in this journal is cited, in accordance with accepted academic practice. No use, distribution or reproduction is permitted which does not comply with these terms. 